\title{
OCULAR TRAUMA IN A TROUBLED ZONE: Northeastern Nigeria
}

\author{
Dr Bh Askira ${ }^{1 *}$, Dr Ma Waziri², Dr Zy Musa ${ }^{3}$ \\ *l Department of Ophthalmology, UMTH, PMB 1414 Maiduguri, Nigeria E-mail: bhaskira@yahoo.co.uk \\ ${ }^{2,3}$ Department of Ophthalmology University of Maiduguri Teaching Hospital, Maiduguri.
}

\section{*Corresponding Author: -}

E-mail: bhaskira@yahoo.co.uk

\begin{abstract}
: -
Introduction: Ocular trauma is an important cause of preventable morbidity worldwide, and is a major cause of unilateral visual loss in developing countries. The eye is the third most common organ affected by injuries, after the hands and the feet

Objective: We present the pattern of ocular injuries in Maiduguri: An armed conflict area.

Material and methods A retrospective study of all the case records of patients with ocular trauma was done between January 2013 and December 2015.

Results: Case note of 108 patients were available for this study. There were $86(66.6 \%)$ males and 22(33.3\%) females. The age range was between 3 years and 60 years of age. The age range 21 to 30 years was predominant 38 (35.2\%). 45 (41.7\%) of the patients presented within the first 24 hours. Blast injuries from improvised explosive devises were seen in $54(50.0 \%)$, gunshot injuries were seen in 25(23.1\%). 27(25.0\%) of the patients had ruptured globe, corneal and corneoscleral lacerations were seen in 19(17.6\%) and 14(13.0\%) respectively. Visual acuity on presentation and visual acuity on last visit of $6 / 18$ or better was seen in $32(31.5 \%)$ and $38(35.2 \%)$ patients respectively, while 62 (57.4\%) and 50 $(46.3 \%)$ had visual acuity of $3 / 60$ or worst on first presentation and on last visit respectively.

Conclusion: The findings from this study highlight a high incidence of severe ocular injury leading to blindness in countries or regions at warA.
\end{abstract}

Key words: OCULAR TRAUMA, CONFLICT, EXPLOSIVE DIVICE, GUNSHOT

\section{(c) $(\$)$}




\section{INTRODUCTION}

Ocular trauma is an important cause of preventable morbidity worldwide, and is a major cause of unilateral visual loss in developing countries ${ }^{1,2,3}$. Eye injuries sustained at work have always been a source of concern to ophthalmologist since the first important survey of eye injuries demonstrated that $71 \%$ of all severe eye injuries admitted to hospitals occurred at the work place, with more than $12 \%$ of these eyes being enucleated ${ }^{4}$. Worldwide, blindness in 1.6 million people is due to ocular trauma, 2.3 million are bilateral low vision patients and 19 million people have unilateral blindness ${ }^{1,5}$.

Despite the fact that the eye represents only $0.1 \%$ of the total body surface 6 , it is the third most common organ affected by injuries ${ }^{7}$, after the hands and the feet. Eye trauma constitutes $7 \%$ of all bodily injuries and $10-15 \%$ of all eye diseases ${ }^{8}$. Significance of the eye to the individuals and the society is disproportionally higher. It is the organ of sight. Loss of which has a great socioeconomic impact on the individual and the society at large.

It may also result into major lifestyle changes, loss of career opportunities and occasionally permanent physical disfigurement.

However, these injuries do not usually occur as random events as some population groups or certain activities of daily living have increased risks of eye injury because of greater exposure to hazard ${ }^{9}$.

The age distribution for the occurrence of serious ocular trauma is bi-modal, with the maximum incidence in young adults and a second peak in the elderly ${ }^{10}$. Both hospital and population-based studies indicate a large preponderance of injuries affecting males ${ }^{11,12,13}$.

Traumatic eye conditions are well known to predominate among occupational injuries ${ }^{9}$. Many eye injuries are related to particular occupations and certain cultures ${ }^{10}$. Farmers on farm land, children at play ground in school, industrial worker working with fast moving machineries and chemical are affected. Both civilian and military personnel are affected in conflict areas.

The eyes have greater risk of injury in conflict than other body parts due to the preferential exposure of the face in combat $^{14}$. The open- globe injuries sustained at war or conflict tend to result in more severe and extensive damage ${ }^{15}$. The damage is usually due to fragmentations that cause penetrating injuries and to the explosive force that causes concussion of the eyeball ${ }^{15}$. Gunshot injuries are common. Mpyet reported gunshot was the commonest cause of ocular injury and was seen $60.9 \%$ of patients ${ }^{16}$.

Most ocular injury studies in Nigeria were done at peace time. We present a pattern of ocular injuries in Maiduguri: A conflict area.

\section{MATERIALS AND METHODS}

Maiduguri is the state capital of Borno, located in North Eastern part of Nigeria. The ophthalmology department of the University of Maiduguri Teaching Hospital (UMTH), a tertiary health facility, serves as a major referral center for eye care in Borno, Yobe , Adamawa states and parts of neighboring Cameroon and Chad. In these states there has been a rising episodes of Military/Boko haram violence with Borno being the epicenter of the violence since 2009 -2015. During this period most of the primary and secondary health facilities were nonfunctional. Thus the bulk of casualties were brought directly to the UMTH center.

A retrospective study of all the case records of patients with ocular trauma was done between January 2013 and Dec 2015. Information extracted includes age, sex, and occupation, time interval of injury before presentation or referral to the eye unit. Presenting complains, presenting visual acuity, nature of injury, circumstance or activity leading to the injury and the causative agent of the injury was extracted. Also obtained from the case note was management modalities' (medical or surgical) and the eventual visual outcome at last visit.

Inclusion criteria

All patients with ocular injuries presenting for the first time to the department of Ophthalmology, UMTH, Maiduguri, during the review period January 2013-December 2015. Ocular Trauma was defined as any injury affecting the eye or adnexae, caused by an external force ${ }^{16}$.

Exclusion criteria

All ocular injury patients who presented for the first time earlier than or later than the study period were excluded from the study.

All data obtained were recorded and analyzed with the statistical package for the social sciences version 15 (SPSS).

\section{RESULTS}

One hundred and thirteen patients were seen with ocular injury in ophthalmology department between 2013 and 2015. Out of these, case note of 108 patients were available for this study. There were $86(66.7 \%)$ males and 22(33.3\%) females. The male to female ratio was $\mathrm{M}: \mathrm{F}=3: 1$. The age range was between 3-60 years of age. The age range 21 to 30 years was predominant $38(35.2 \%)$. The age and sex distribution is as shown in table 1 .

The time of presentation of patients from the onset of trauma is as shown in table $11.45(41.7 \%)$ of the patients presented within the first 24 hours, $38(35.2 \%)$ in the first one week, and $12(11.1 \%)$ presented within one month of injury.

Blast injuries from improvised explosive devises were seen in 54(50.0\%), gunshot injuries were seen in $25(23.1 \%)$, road traffic accident 21(19.4\%), while other mechanism of ocular injuries in this study includes domestic accidents 3(\%), burns $2(1.9 \%)$, Cow horn injury $1(0.9 \%)$, blow from a fight $1(0.9 \%)$ and whiplash affecting the eye $1(0.9 \%)$.

Diagnosis on admission was as shown in table 111. Many of the patients had multiple injuries. 27(25.0\%) of the patients had ruptured globe, lid laceration were seen in $9(8.3 \%)$, corneal and corneoscleral laceration were seen in $19(17.6 \%)$ and $14(13.0 \%)$ respectively. 
Visual acuity on presentation and visual acuity on last visit of $6 / 18$ or better was seen in $32(31.5 \%)$ and $38(35.2 \%)$ patients respectively, while $62(57.4 \%)$ and $50(46.3 \%)$ had visual acuity of 3/60 or worst on first presentation and on last visit respectively. Table $1 \mathrm{~V}$ shows visual acuity distribution on first presentation and on last visit, while table $\mathrm{V}$ shows the different types of intervention done.

Table 1: AGE AND SEX DISTRIBUTION OF 108 OCULAR INJURY PATIENTS

\begin{tabular}{|l|l|l|l|}
\hline AGE GROUG & $\begin{array}{l}\text { MALES } \\
\text { number }(\%)\end{array}$ & $\begin{array}{l}\text { FEMALES } \\
\text { number }(\%)\end{array}$ & $\begin{array}{l}\text { Total males } \\
\text { and females }\end{array}$ \\
\hline $0-10$ & $12(11.1 \%)$ & $8(7.4 \%)$ & $20(18.5 \%)$ \\
\hline $11-20$ & $6(5.5 \%)$ & $5(4.6 \%)$ & $11(10.2 \%)$ \\
\hline $21-30$ & $31(28.7 \%)$ & $7(6.5 \%)$ & $38(31.2 \%)$ \\
\hline $31-40$ & $21(19.4 \%)$ & $2(1.9 \%)$ & $23(21.3 \%)$ \\
\hline $41-50$ & $12(11.1 \%)$ & $0(0.0 \%)$ & $12(11.1 \%)$ \\
\hline $51-60$ & $4(3.7 \%)$ & $0(0.0 \%)$ & $4(3.7 \%)$ \\
\hline TOTAL & $86(66.7 \%)$ & $22(33.3 \%)$ & $108(100 \%)$ \\
\hline
\end{tabular}

Table 11: TIME OF PRESENTATION OF PATIENTS TO THE HOSPITAL FROM THE ON SET OF INJURY

\begin{tabular}{|l|l|}
\hline TIME OF PRESENTATION & NUMBER $(\%)$ \\
\hline First 24 hours & $45(41.7 \%)$ \\
\hline After 24hrs but within seven days & $38(35.2 \%)$ \\
\hline After seven but within one month & $12(11.1 \%)$ \\
\hline Greater than one month & $9(8.3)$ \\
\hline Not stated & $4(3.7 \%)$ \\
\hline TOTAL & $108(100 \%)$ \\
\hline
\end{tabular}

Table 111: DIAGNOSIS ON ADMISSION

\begin{tabular}{|l|l|l|}
\hline S/number & Diagnosis on admission & Number (\%) \\
\hline 1 & Ruptured globe & $27(25.0 \%)$ \\
\hline 2 & Corneal laceration & $19(17.6 \%)$ \\
\hline 3 & Corneo scleral laceration & $14(13.0 \%)$ \\
\hline 4 & Lid laceration & $9(8.3 \%)$ \\
\hline 5 & Sub conjunctival hemorrhage & $9(8.3 \%)$ \\
\hline 6 & Corneal foreign body & $6(5.6 \%)$ \\
\hline 7 & Traumatic conjunctivitis & $6(5.6 \%)$ \\
\hline 8 & Hyphaema & $5(4.6 \%)$ \\
\hline 9 & Traumatic cataract & $4(3.7 \%)$ \\
\hline 10 & Cranial nerve palsy & $2(1.9 \%)$ \\
\hline 11 & Corneal opacity & $2(1.9 \%)$ \\
\hline 12 & Optic atrophy & $2(1.9 \%)$ \\
\hline 13 & Intra orbital foreign body & $1(0.9 \%)$ \\
\hline 14 & Corneal burns & $1(0.9 \%)$ \\
\hline 15 & Orbital rim fracture & $1(0.9 \%)$ \\
\hline
\end{tabular}

Table 1V: Distribution of visual acuity on first presentation and on last visit

\begin{tabular}{|l|l|l|}
\hline Visual acuity & $\begin{array}{l}\text { Number (\%) on } \\
\text { presentation }\end{array}$ & $\begin{array}{l}\text { Number (\%) on last } \\
\text { visit }\end{array}$ \\
\hline Greater than 6/18 & $32(31.5 \%)$ & $38(35.2 \%)$ \\
\hline $6 / 18-6 / 60$ & $4(3.7 \%)$ & $12(\mathrm{i} 11.1 \%)$ \\
\hline $5 / 60-3 / 60$ & $6(5.5 \%)$ & $4(3.7 \%)$ \\
\hline Less than $3 / 60$ & $62(57.4 \%)$ & $50(46.3 \%)$ \\
\hline No record & $4(3.7 \%)$ & $4(3.7 \%)$ \\
\hline Total & $108(100 \%)$ & $108(100 \%)$ \\
\hline
\end{tabular}


Table V: Interventions on admission

\begin{tabular}{|l|l|l|}
\hline S/ Number & $\begin{array}{l}\text { Intervention on } \\
\text { admission }\end{array}$ & Number (\%) \\
\hline 1 & Medical & 25 \\
\hline 2 & Evisceretion & 27 \\
\hline 3 & Corneal repair & 19 \\
\hline 4 & Corneo-scleral repair & 14 \\
\hline 5 & Lid repair & 8 \\
\hline 6 & Foreign body removal & 6 \\
\hline 7 & Catatact extraction & 4 \\
\hline 8 & Referred to other centers & 4 \\
\hline 9 & Refused surgery & 1 \\
\hline 10 & No record & 4 \\
\hline 11 & Total & $108(100 \%)$ \\
\hline
\end{tabular}

\section{DISCUSSION}

Ocular trauma once described as the neglected disorder ${ }^{17}$ has recently been highlighted as a major cause of visual morbidity. Globally more than half a million blinding injuries occur every year ${ }^{18}$

We retrospectively evaluated 108 patients' case notes at the ophthalmology department of UMTH. There was a male $(66.7 \%)$ preponderance in this study. Similar male preponderance has been reported in ocular traumas ${ }^{12,13,19,20}$. Several reasons may have accounted for this. First there has been the argument that more male are involve in high risk behavior and vocation, and are more adventurous and aggressive which makes them more prone to ocular Injuries ${ }^{21}$. In addition to these, this study was done in an armed conflict zone particularly over the period of study.

The age group 21-30 constituted $35.2 \%$ of the study population. Adeoye $\mathrm{e}^{14}$ reported $46.3 \%$ of ocular injuries occurred in age group 21-30 years in a communal conflict-related ocular trauma in Ile-Ife. Oluyemi ${ }^{3}$ reported $41.5 \%$ in their series age less than 15 years old. In this study and that of Adeoye ${ }^{14}$, the studies were done in an armed conflict zone. This must have influenced the preponderance of young and active age group involved in this type of conflict.

The interval between injury and presentation varied considerably. $41.7 \%$ of the patients presented within the first 24 hours of injury, while $35.2 \%$ presented after 24 hours but within first 7 days of injury. $11.1 \%$ presented after one week but within one month of injury. Omolase et-al ${ }^{22}$ reported $37.9 \%$ of their series reported within the first 24 hours of injury. Proximity to eye center and awareness of eye services within the center have been cited as likely reasons for early reporting of injuries. Our study was done in a sensitized armed conflict zone with enhanced reporting of injured persons on battle field to health facilities. Undoubtedly early reporting and institution of appropriate intervention will decrease morbidity and improve visual outcome. Our findings are in contrast with those reported by Umeh and Umeh ${ }^{23}$. $28.5 \%$ of their series reported within the first 24 hours and as many as $10.5 \%$ reporting after one month of injury. They noticed a general delay in reporting to the hospital in all types and severity of injuries.

Duke Elder states that explosives injuries to the eye do occur in civilians but they are more common in war, when they are most usually by the bursting of shells, bombs, grenades or berried mines ${ }^{24}$. The incidence of severe ocular injury leading to blindness in countries at war or with high landmine densities has not been formally evaluated, but reports suggest that it is much higher than in countries at peace ${ }^{25}$. Blast injuries from explosive devices and gunshot injuries were seen in $50.0 \%$ and $25 \%$ respectively together constituting about $75 \%$ of all ocular injuries in this study. This preponderance of explosive and gunshot injuries in this study is due to the fact that there has been a rising episodes of military/boko haram violence during the study period. Domestic accidents were seen in only 3\%. This is in contrast to report by Oluyemi ${ }^{3}$ who reported that majority of the injuries occurred as household accidents. . Emem ${ }^{6}$ reported physical assault in form of slap, fist blow during a fight as the commonest cause of ocular injury seen in $62.2 \%$

The eyes have greater risk of injury in conflict than other parts of the body due to preferential exposure of the face in combat $^{14}$. Open globe injuries sustained at war or conflict tend to result in more severe and extensive damage ${ }^{15}$. Ruptured globe, corneal and corneoscleral laceration together constituted $55.6 \%$ in this study. Ohumwangho et-al ${ }^{4}$ in a study on occupational eye injury among sawmill workers in Nigeria reported the common form of ocular trauma seen was superficial conjunctiva or corneal foreign body (71.2\%). These variations in preponderance of type of ocular injury may be due to difference in population studied and either in peace time or conflict time. Our study was done in a conflict zone. This has no doubt influence the type of ocular injuries seen.

Ocular trauma remains an important cause of preventable and predominantly monocular visual morbidity and blindness $^{3}$.Sudden blindness in an otherwise healthy young man is devastating, as vision is the most important sense, accounting for more than $90 \%$ of the total sensory input ${ }^{26}$.

The overall visual acuity of $6 / 18$ or better was seen $31.5 \%$ and $35.2 \%$ on first presentation and on last visit respectively in this study. While those with visual acuity of $3 / 60$ or less on first presentation and on last visit were $57.4 \%$ and $46.3 \%$ respectively. Low visual outcome was not surprising considering the majority of the ocular traumas in this study were penetrating eye injuries from explosive devises and gunshot. 


\section{CONCLUSION:}

The findings from this study highlight incidence of severe ocular injury leading to blindness in countries or regions at war. There is the need for institutional strengthening to take care of such casualties when they do occur.

\section{REFERENCES}

[1].Negrel AD, Thylefors B. The global impact of eye injuries. Ophthalmic Epidemiol 1998;5:143169

[2].Thylefors B. Epidemiological patterns of ocular trauma. Aust N Z J Ophthalmol 1992; 20:95-98

[3].Oluyemi F. Epidemiology of penetrating eye injury in Ibadan: A 10-year hospital based review. Middle East African Journal of Ophthalmology 2011;18:2 p 159-163

[4].Uhumwangho OM, Njinaka I, Edema OT, Dawodu OA, Omoti AE. Ocupational eye injury among sawmill workers in Nigeria. Asian journal of Medical Sciences 2010; 2(5): 233-236

[5].Kinderan YN, Shrestha E, Maharjan IM, Karmacharya S. Pattern of ocular trauma in Western Region of Nepal. Nepal J Ophthalmol 2012; 4(7): 5-9

[6].Emem A, Uwemedimbuk E. Prevalence of traumatic ocular injuries in a teaching hospital in South-South Nigeria- A two year review. Advance Tropical Medicine and Public Health International 2012; 2(3): 102-108

[7].Nordber E. Ocular injuries as a public health problem in sub-saharan Africa: Epidemiology and prospect for control. East Afr Med. J 2000; 77: 1-43

[8].Acar U, Tok OY, Acar DE, Burcu A, Ornek. A new ocular trauma score in pediatric penetrating eye injuries. Eye $2011 ; 25: 370-374$

[9].Okoye OI. Eye injury requiring hospitalization in Enugu, Nigeria. A one-year survey. Nigerian Journal of Surgical Research. 2006; 8(1-2): 34-37

[10]. Desai P, MacEwen CJ, Baines P, Minaissian DC. Epidemiology and implications of ocular trauma admitted to hospital in Scotland. J Epidemiol Community Health 1996; 50(4): 436-441

[11]. MacEwen CJ. Eye injuries: a prospective survey of 5671 cases. British Journal of Ophthalmology 1989;73(11): 888894

[12]. Katz J, Teilsch JM. Lifetime prevalence of ocular from the Baltimore Eye Survey. Achieves of Ophthalmology 1993; 111(11): 1564-1568

[13]. Macewen CJ. Ocular injuries. Journal Royal College of Surgeons of Edinburgh 1999; 44(5): 317323

[14]. Adeoye AO, Olateju EO, Soetan EO. Communal conflict-related ocular trauma. Nigerian Journal of Clinical Practice 2000; 5(1): 1-4

[15]. Sobaci G, Mutlu FM, Bayer A, Karagul S, Yildirim E. Deadly weapon-related open-globe injuries: Outcome assessment by the ocular trauma classification system. American Journal of Ophthalmology 2000; 129(1): 47-53

[16]. Mpyet CD, Alli S, Wade P, Agaba B. Ocular injuries in a civilian conflict in jos. Nigerian Journal of Ophthalmology 2004; 12(1): 10-13

[17]. Parver L, Eye trauma. The neglected disorder. Arch Ophthalmol 1986; 104(10): 1452-1453

[18]. Macewen CJ. Ocular injuries. JR Coll. Surg. Edinb.1999; 44: 317-323

[19]. Olurin O. Eye injuries in Nigeria. Am J Ophthalmol 1971; 72(1): 157-166

[20]. Adeoye AO. Eye injuries caused by locally manufactured dane-guns. Nig J Ophthalmol 1996; 4(1): 27-30

[21]. Ajaiyeoba AI. Ocular injuries in Ibadan. Niger J Ophthalmol 1995; 2: 18-24

[22]. Omolase CO, Omolade EO, Ogunleye OT, Omolase BO, Ihemedu CO, Adeosun OA. Pattern of ocular injuries in Owo, Nigeria. Journal of ophthalmic and visual research 2011; 6(2): 114-118

[23]. Umeh RE, Umeh OC. Causes and outcome of childhood eye injuries in Nigeria. Eye 1997; 11: 489-495

[24]. Duke-Elder S. Explosion and gunshot injuries. System of Ophthalmology, vol 14. London; H. Kimpton $1972 ; 671$

[25]. Heather J. Severe ocular trauma due to land mines and other weapons in Cambodia. Community Eye Health 1997; 10(2): 37-39

[26]. Wong TY, Seet B, Ang CL. Eye injuries in twentieth century warfare: A historical perspective. Surv Ophthalmol 1997; 41(6): 433-459 